\title{
Bony labyrinth morphology in early neopterygian fishes (Actinopterygii: Neopterygii)
}

\begin{tabular}{|r|l|}
\hline Journal: & Journal of Morphology \\
\hline Manuscript ID & JMOR-16-0037.R1 \\
\hline Wiley - Manuscript type: & Research Article \\
\hline Date Submitted by the Author: & n/a \\
\hline Complete List of Authors: & $\begin{array}{l}\text { Giles, Sam; University of Oxford, Department of Earth Sciences } \\
\text { Rogers, Molly; University of Oxford, Department of Zoology } \\
\text { Friedman, Matt; University of Oxford, Department of Earth Sciences }\end{array}$ \\
\hline Keywords: & $\begin{array}{l}\text { Actinopterygii, computed tomography, Neopterygii, semicircular canals, } \\
\text { bony labyrinth }\end{array}$ \\
\hline &
\end{tabular}


Giles 1

2

3

4

5

6

7

8

9

10

11

12

13

14

15

16

17

18

19

20

21

22

23

24

25

26

27

28

29

30

31

32

33

34

35

36

37

38

39

40

41

42

43

44

45

46

47

48

49

50

51

52

53

54

55

56

57

58

59

60

Bony labyrinth morphology in early neopterygian fishes (Actinopterygii: Neopterygii)

Sam Giles $^{\mathrm{a}}$, Molly Rogers ${ }^{\mathrm{b}}$, Matt Friedman ${ }^{\mathrm{a}}$

${ }^{\mathrm{a} D e p a r t m e n t ~ o f ~ E a r t h ~ S c i e n c e s, ~ U n i v e r s i t y ~ o f ~ O x f o r d, ~ O x f o r d, ~ U K, ~ O X 1 ~ 3 A N ~}$

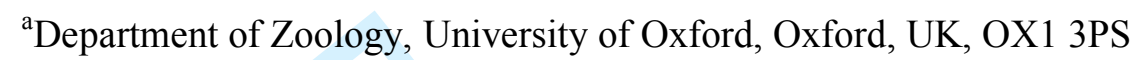

*Correspondence to: Sam Giles, +44 (0) 1865 282117, sam.giles@earth.ox.ac.uk, Department of Earth Sciences, University of Oxford, Oxford, UK, OX1 3AN

Short title: Neopterygian bony labyrinths

John Wiley \& Sons 
Giles 2

ABSTRACT

KEY WORDS: (3-6) Actinopterygii; computed tomography; endocast; bony labyrinth; Neopterygii; semicircular canals. 


\section{INTRODUCTION}

The bony labyrinth of jawed vertebrates includes three semicircular canals (anterior, posterior and horizontal) that contribute to the inner ear. These canals are instrumental in detecting head movement and rotation, and communicating such inputs to the brain. The outer canals (typically formed in bone, although they may be continuous with the rest of the cranial cavity) house a membranous duct filled with endolymphatic fluid and tethered to the bony canals by means of membranous connections (de Burlet, 1934). The space between the membranous and bony canal is filled with perilymphatic fluid, which has inertia. Movement of the head causes a current in this fluid, which in turn deforms the cupula, a diaphragm within the canal's ampulla that is covered in cilia. This deformation is transmitted to the brain via the vestibulocochlear (VIII) cranial nerve.

The labyrinth, in particular the morphology of the semicircular canals, represents important evidence for understanding the history of movement and behavioural adaptations in fossil and extinct groups, as demonstrated for taxa as diverse as dinosaurs (e.g. Rogers, 1999), cetaceans (Spoor et al., 2002), and hominids (e.g. Spoor et al., 1994; see also general review in Hullar, 2006). However, studies of comparable scope in actinopterygians (ray-finned fishes) are hampered by a conspicuous failure to collect primary data on labyrinth morphology. Retzius (1881) remains the most comprehensive account to date, describing the inner ear in the sturgeon Acipenser, the gar Lepisosteus, the bowfin Amia and a number of teleosts. Several surveys of labyrinth measurements in extant fishes were carried out in the 1960s and '70s (Jones \& Spells, 1963; ten Kate, 1969; ten Kate et al. 1970; Howland \& Masci 1973a,b; see also Gauldie \& Radtke, 1990), but were conducted primarily with the aim of testing the theoretical underpinning 
of how the ear detects angular acceleration. In addition, these past investigations focussed almost exclusively on just two measurements: R, radius of curvature of the bony canal; and $r$, radius of curvature of the membranous canal; demonstrated to account for much of the variability observed in canal sensitivity (Jones \& Spells, 1963). More recently, sporadic accounts of inner ear anatomy have targeted isolated taxa such as perch (Perca: Ladich \& Popper, 2004), arrowana (Osteoglossum: Popper et al., 2003), and a number of catfishes (e.g. Ictalurus: Jenkins, 1977; Arius: Popper \& Tavolga, 1981; Pterygoplichthys: Rogers, 2008).

While some data have been collected for extant taxa, understanding of bony labyrinth anatomy is even more scant for extinct species, with Bernacsek \& Carroll (1981) presenting one of the only analyses of semicircular canal size in fossil fishes (including seven actinopterygians). This is largely due to the paucity of reconstructions in the literature, despite a relatively large number of candidate specimens. Labyrinth morphology has been described for just two Devonian actinopterygians, Mimipiscis (Giles \& Friedman, 2014) and Raynerius (Giles et al., 2015), although the latter is incompletely preserved. A further four are known from the Carboniferous: Kansasiella (Poplin, 1974), Kentuckia (Giles \& Friedman, 2014), Lawrenciella (Hamel \& Poplin, 2008), and an unnamed actinopterygian from which only a rudimentary interpretation of labyrinth morphology can be drawn (Moodie 1929). None are described from the Permian. A larger number of descriptions (of varying completeness) of the bony labyrinth and associated structures are known from the earliest Triassic, reflecting a series of productive fossil fish localities yielding three-dimensional material and studied largely either through serial grinding or examination of natural moulds: Saurichthys 
ornatus, S. wimani, and S. hamiltoni (Stensiö, 1925: figs 9, 49) from Spitzbergen; Boreosomus gillioti, Devillersia madagascariensis, Pteronisculus sp., and Watsonulus sp. (Beltan, 1968: figs 7, 28, 39-40) from Madagascar; Ospia sp. (Stensiö, 1932: fig.74), Australosomus kochi (Nielsen, 1949: figs 17-19), B. piveteaui and P. stensioi (Nielsen, 1942: figs 13-16, 66) from Greenland. A handful of labyrinths have also been reconstructed in more stratigraphically recent taxa: Dorsetichthys bechei (Patterson, 1975: fig. 66) and 'Caturus' sp. (Rayner, 1948: fig. 9) from the Early Jurassic; Caturus groenlandicus (Aldinger, 1932: fig. 2) and Ionoscopus cyprinoides (Maisey, 1999: fig. 10) from the Late Jurassic; and Calamopleurus cylindricus (Maisey, 1999: fig. 66) and Notelops brama (Dunkle, 1940: fig. 6) from the Early Cretaceous.

Of existing models of labyrinth morphology in fossil actinopterygians, the most complete examples belong to taxa that fall outside the neopterygian (holostean + teleost) crown, and consequently cannot easily be related to living groups. Fossil neopterygian labyrinth anatomy is best known in Caturus groenlandicus (Aldinger 1932; Fig. 1A), where the endocast is preserved as a 'steinkern' (or natural internal mould), and 'Caturus' sp. (an indeterminate halecomorph referred to Caturus by Rayner 1948 (Fig. 1B), where half of the braincase was serially sectioned and a model of the endocast produced. This latter example lacks many of the features present in the type species C. furcatus (e.g. sutural division of the braincase; see discussion in Patterson, 1975). Such problems of attribution characterise other thoroughly described early neopterygian braincases, which are often known in isolation from other parts of the skeleton (Patterson, 1975).Accounts of labyrinth morphology in other neopterygians are largely based on fragmentary material (e.g. Beltan, 1968; Fig. 1C-E and Stensiö, 1932; 
Fig. 1F), examination of the labyrinth cavity (e.g. Patterson, 1975; Fig. 1G), and extrapolation from the anatomy of extant taxa (e.g. Maisey, 1999; Fig. 1H,I). This is despite a large number of well-preserved, mechanically- and acid-prepared braincases from the Mesozoic (e.g. Rayner, 1948; Gardiner, 1960; Patterson, 1975).

In addition to providing primary data on canal morphology and potentially the behavioural history of the group, it is to be expected that a detailed description of the inner ear in neopterygians--and fishes more generally--will provide anatomical characters of use in reconstructing phylogenetic relationships. While it has been shown that specific variables such as $\mathrm{R}$ and $\mathrm{r}$ do not correlate with taxonomic groupings (Howland \& Masci, 1973a), studies in other lineages have found numerous anatomical characteristics of the endoskeletal labyrinth that support the monophyly of major clades (e.g., chondrichthyans: Maisey, 2001; afrotherian mammals: Benoit et al. 2015; strepsirrhine primates: Lebrun et al., 2010; xenarthran mammals: Billet et al. 2015). This potential to provide an increased morphological character set is of particular importance given the current state of comprehension of relationships among early neopterygians. While there is consensus on the branching pattern of the three major extant neopterygian lineages based on both molecular (Near et al., 2012) and morphological (Grande, 2010) evidence, the placement of some fossils deep within neopterygian phylogeny are less certain. Dapedium is variably considered a total-group holostean (e.g., Schaeffer, 1967; Tintori, 1983; Thies \& Herzog, 1999; Thies \& Waschkewitz, in press) or stem teleost (e.g., Olsen, 1984; Gardiner et al., 1996; Hurley et al., 2007; Xu \& Wu, 2012); pycnodonts have been intepreted as both stem teleosts (e.g., Gardiner et al. 1996; Hurley et al., 2007; Nursall, 2010; Friedman 2012) and stem 
neopterygians (e.g., Poyota-Ariza, 2015); and parasemionotids have been resolved as both crown-group holosteans (e.g., Patterson, 1973, 1975, 1977; Wiley 1976; Grande \& Bemis, 1998) and as stem neopterygians (e.g., Olsen, 1984).

Here we use CT scanning to present a preliminary study of labyrinth morphology in eight fossil neopterygians, the braincases of all but one of which (Elopoides) have previously been described on the basis of external morphology (see Rayner, 1948 and Patterson, 1975; endocast and braincase anatomy on the basis of CT scanning will be considered in a later publication). This report seeks to determine whether the morphology of the labyrinth and associated features in neopterygians is sufficiently rich in characters to be of use when reconstructing phylogenetic relationships, while setting the framework for future, more data-rich analyses focussing on both phylogenetic and ecological patterns. It will also test the hypotheses of labyrinth anatomy advanced by Rayner (1948) for 'Caturus' sp. and Patterson (1975) for Dorsetichthys bechei, providing explicit examples of the degree to which labyrinth reconstructions derived from different analytical approaches might be comparable.

\section{MATERIALS AND METHODS}

\section{Institutional/Geographic Abbreviations}

Specimens are curated in the Natural History Museum, London, UK (NHMUK), Mineralogisk Museum, Copenhagen, Denmark (MGUH), Muséum national d'Histoire naturelle, Paris, France (MNHN), and Bath Royal Literary and Scientific Institute, Bath, UK (BRLSI). 
Giles 8

\author{
Materials \\ SUBCLASS NEOPTERYGII Regan, 1923 \\ INFRACLASS HOLOSTEI Müller, 1844 \\ SUBDIVISION HALECOMORPHI Cope, 1872
}

Neurocrania of four halecomorph taxa were studied. The first is the acid-prepared braincase of an undetermined parasemionotid from the Early Triassic (Induan) of east Greenland (MGUH 492), previously described by Patterson (1975:p.434). The second is Heterolepidotus sp. from the Early Jurassic (Sinemurian) of Charmouth, UK (NHMUK PV P.13260), also represented by a single, acid-prepared braincase and described by Patterson (1975: p.436). 'Caturus' sp. from the Early Jurassic (Toarcian) of Somerset, UK (BRSLI M.1288A) has been described by Rayner (1948:p.293) on the basis of an isolated neurocranium, prepared mechanically and subjected to physical tomography. 'Aspidorhynchus' sp. from the Middle Jurassic (Bathonian) of Northampton, UK (NHMUK PV P.9844) is represented by a mechanically prepared braincase, initially described by Smith Woodward (1918). Despite being referred to Aspidorhynchus sp. by Rayner (1948: p.314), Patterson (1975:p.286) notes that this and another specimen from the same locality most likely belong to a new genus, and provides an additional description of the material (1975:p.436).

\title{
INFRACLASS TELEOSTEI Müller, 1844
}

Dorsetichthys bechei from the Early Jurassic (Sinemurian) of Charmouth, UK, is known from numerous complete specimens. The braincase studied here (NHMUK PV P.1052) is acid prepared, and the subject of a description by Patterson (1975:p.321). The braincase of 'Pholidophorus' sp. from the Middle Jurassic (Callovian) of France 
(NHMUK PV P.32579) is isolated, and appears to have not been collected in situ (Patterson 1975:p.284). The specimen was briefly referred to by Smith Woodward (1895) and Wenz (1968), and more fully described by Patterson (1975:p.288). Elopoides tomassoni from the Early Cretaceous (Albian) of Aube, France (MNHN CTE 14), is known from a complete skull and the anterior portions of the trunk. Wenz (1965) described this taxon on the basis of external morphology alone, providing no details of the endocranium.

\section{NEOPTERYGII INCERTAE SEDIS}

We studied an acid-prepared specimen of Dapedium sp. from the Early Jurassic (Sinemurian) of Charmouth, UK (NHMUK PV P.11177). Patterson provides a reconstruction of neurocranial anatomy in Dapedium that draws heavily on this specimen (1975:p.455), which was previously investigated by Frost (1913), Rayner (1948) and Gardiner (1960).

\section{Methods}

Most specimens were scanned at the Imaging and Analysis Centre, NHMUK, using a Metris X-Tek HMX ST 225 CT System with a 2000 x 2000 pixel detector, tungsten reflection target, and 3142 projections, using the following parameters: parasemionotid: $180 \mathrm{kV}, 160 \mu \mathrm{A}, 0.25 \mathrm{~mm}$ thick copper filter, voxel size $12.2 \mu \mathrm{m}$; Heterolepidotus sp.: $205 \mathrm{kV}, 155 \mu \mathrm{A}, 3 \mathrm{~mm}$ thick copper filter, voxel size $41.9 \mu \mathrm{m}$; 'Caturus' sp.: kV, $\mu \mathrm{A}$, mm thick xx filter, voxel size $\mu \mathrm{m}$; 'Aspidorhynchus': $205 \mathrm{kV}, 180 \mu \mathrm{A}, 1 \mathrm{~mm}$ thick copper filter, voxel size $59.7 \mu \mathrm{m}$; Dapedium sp.: $175 \mathrm{kV}, 165 \mu \mathrm{A}, 0.5 \mathrm{~mm}$ thick copper filter, voxel size $40.9 \mu \mathrm{m}$; Dorsetichthys bechei: $175 \mathrm{kV}, 160 \mu \mathrm{A}, 0.5 \mathrm{~mm}$ thick copper 
filter, voxel size $18.6 \mu \mathrm{m}$; 'Pholidophorus' sp.: $185 \mathrm{kV}, 160 \mu \mathrm{A}, 0.5 \mathrm{~mm}$ thick copper filter, voxel size $21 \mu \mathrm{m}$. Elopoides was scanned using a GE Phoenix v|tome|x $240 \mathrm{~L}$ in the AST-RX unit, MNHN, with the following settings: $130 \mathrm{kV}, 400 \mu \mathrm{A}, 0.5 \mathrm{~mm}$ thick copper filter, voxel size $59.8 \mu \mathrm{m}$.

Scans were manipulated and manually segmented in Mimics version 18.01 (biomedical.materialise.com/mimics; Materialise, Leuven, Belgium). Meshes were exported as .ply surface files and imaged in Blender (blender.org). These files are available as part of the online supporting materials.

\section{RESULTS}

\section{Holostei}

Undertermined parasemionotid (Figs. 2A,B and 3A,B). The roof of the braincase is damaged, and consequently the labyrinth is incompletely preserved on both sides. Little can be said about the course of the anterior semicircular canal, but the anterior ampulla is well developed. The utriculus is rounded and fairly shallow. The horizontal canal is inclined, and its ampulla is distinct from the utriculus. Posteriorly, the horizontal canal communicates with the cranial cavity through the same opening as the posterior ampulla, but the path of the horizontal canal can be traced some way within the ampulla. As the lateral cranial canal is incomplete it cannot be fully described, and it is unclear whether it was confluent with the cranial cavity anteriorly as well as posteriorly. The cranial cavity and lateral cranial canal are not widely separated. The sacculus is deep, and opens into the large vestibular fontanelle. The hind margin of the otic capsule 
is marked by the exit of the vagus $(\mathrm{CN} \mathrm{X})$ nerve, which left the cranial cavity through a fairly large, rounded canal.

Heterolepidotus (Figs. 2C,D and 3C,D). The labyrinth is completely preserved in Heterolepidotus, with all three semicircular canals fully enclosed in bone, although sheets of pyrite pervading the specimen occasionally obscure some aspects. The anterior semicircular canal is long and shallow, such that the long axis of the anterior ampulla is horizontally oriented. The crus commune of the anterior and posterior canals sits level with the endocranial roof, and there is a moderately large separation between the left and right crus. Although incompletely preserved on the left side, the utriculus is fairly deep, with an elongate dorsoventral axis. Posteriorly, the horizontal canal is confluent with the posterior ampulla, but the path of the canal is delimited by a slight constriction. The lateral cranial canal is rounded, with a small ventral lobe. There is relatively little separation between the lateral cranial canal and the lateral wall of the cranial cavity, and communication is through the loops of both the anterior and posterior semicircular canals. The root of the vagus $(\mathrm{CN} \mathrm{X})$ nerve is large and anteroposteriorly long.

'Caturus' (Figs. 2E,F and 3E,F). Only one half of this specimen survives; its antimere was investigated via destructive serial sectioning by Rayner (1949). The braincase is well mineralised and the labyrinth completely preserved. All three semicircular canals are completely invested in bone. The canals are of a similar length, although the anterior canal is slightly longer. The crus commune is set into the lateral portion of the cranial roof, rather than projecting above it. The ampulla of the anterior canal is moderately well developed and its long axis oriented vertically. In contrast, the horizontal ampulla 
is indistinct. Instead of entering the cranial cavity independently, the horizontal canal runs into the ampulla of the posterior canal. It is not possible to trace the course of the canal once it joins the posterior ampulla. The utriculus is deep, and the sacculus bears a posterior extension delimited by a distinct notch. The lateral cranial canal is narrow, with a fairly large separation between it and the lateral wall of the cranial cavity. Although it is confluent with the remainder of the cranial cavity anteriorly and posteriorly, the anterior connection is very small. Its shape is very irregular, with medial, anterolateral and ventral diverticulae. A dorsally directed canal lateral to the crus commune marks the route of the endolymphatic duct. The root of the vagus (CN X) nerve is robust and anteroposteriorly long.

'Aspidorhynchus' (Figs. 2G,H and 3G,H). The labyrinth in 'Aspidorhynchus' is completely preserved, and all canals are fully enclosed in bone. Of the three canals, the anterior is the longest, and joins the posterior in a crus commune that extends dorsal to the roof of the endocranial cavity. The angle of the anterior semicircular canal is so shallow that the long axis of the anterior ampulla is oriented almost horizontally. The left and right crus commune are very closely set, separated by only a narrow portion of the cranial cavity. A distinct posterodorsal diverticulum is present on the posterior canal. The horizontal canal is inclined at angle of around 30 degrees from the horizontal plane, and posteriorly joins the ampulla of the posterior canal before entering the cranial cavity. Both the anterior and horizontal canal bear rather poorly developed ampullae, connected via a dorsoventrally deep utriculus. The sacculus is antero-posteriorly elongate, with a posteroventral extension. Large openings allow the lateral cranial canal to communicate with the cranial cavity through the loops of both the anterior and 
posterior canal, and a spur-like ventral diverticulum is present. Posterior to the labyrinth, the root of the vagus $(\mathrm{CN} \mathrm{X})$ nerve is large with a long anteroposterior axis.

\section{Incertae sedis}

Dapedium (Figs. 4A,B and 5A,B). The specimen has suffered some damage, with the dorsal portion of the braincase missing behind the orbit, but the labyrinth is complete. All three semicircular canals are invested in bone. Although the anterior semicircular canal is slightly longer, all three canals are of a similar length, and have small but well developed ampullae. The long axis of the anterior ampulla is near-vertically aligned. As well as projecting some way above the endocranial roof, the left and right crus commune are closely set, approaching the midline. The utriculus is small but dorsoventrally deep, and a slight constriction subdivides it into dorsal and ventral components. In addition to bearing a spur-like posterior extension, the sacculus is notched both anteriorly and posteriorly, creating a dorsal constriction. The horizontal canal sits entirely within the horizontal plane. While the horizontal canal and posterior ampulla share a common opening into the endocranial cavity, the path of the horizontal canal is separated from the ampulla by a slight constriction along its entire length. The lateral cranial canal is very large, projecting well above the roof of the cranial endocavity, with wide connections through the loop of the anterior and posterior semicircular canals. In addition, it has both dorsal and ventral extensions, the latter with a horizontal component. Two canals extending from the roof of the endocranial cavity transmit what we identify as endolymphatic ducts into an extensive median sinus (not figured here). The root of the vagus ( $\mathrm{CN} \mathrm{X})$ nerve is fairly large, and is long and narrow at its base. 


\section{Teleosts}

Dorsetichthys (Figs. 4C,D and 5C,D). The labyrinth is almost completely preserved, with only the left sacculus and horizontal canal unknown. Each of the three semicircular canals is fully enclosed in bone, although there is almost no separation between the bone surrounding the anterior canal and that of the endocavity. In addition, the crus commune is set very closely into the endocavity, projecting only slightly above the endocranial roof. The anterior canal is the longest of the three, and the long axis of its ampulla is near-horizontal. In contrast, the horizontal canal is very short. All three canals have large, rounded ampullae, and the posterior ampulla completely engulfs the posterior portion of the horizontal canal. The utriculus is also rounded. As the posterior limit of the sacculus is missing on both sides of the specimen its shape cannot be fully described, but it appears small with no anterior extensions. A very thin sheet of bone separates the lateral cranial canal from the cranial cavity. The shape of the canal itself is irregular, with both dorsal and ventral extensions. The morphology of the vagus (CN X) nerve is unknown.

'Pholidophorus' (Figs. 4E,F and 5E,F). The specimen is well preserved, missing only the anterior-most part of the endocast. Only the horizontal semicircular canal is completely enclosed in bone. Significant portions of the remainder of the labyrinth are accommodated within the endocranial cavity, in particular the medial wall of the anterior and posterior canals. As such it is difficult to describe their paths, but the anterior canal appears to be fairly long and shallow, with the long axis of its ampulla being horizontally oriented. Both the anterior and horizontal ampullae are large and 
swollen. The crus commune is wholly contained within the cranial cavity. The utriculus is fairly deep but rounded, and is poorly separated from the sacculus. The sacculus is deep and narrow, with an anterior notch and a posterior swelling. The posterior canal bears a large, elongate ampulla, into which the horizontal canal opens, although its path can be clearly traced up to its junction with the cranial cavity. As with the whole endocast, the horizontal canals are latero-medially wide, with the anterior and posterior limbs being almost isoclinal. The lateral cranial canal is dorsoventrally extensive and dorsally positioned, projecting some little way above the roof of the endocast. Only a very thin sheet of bone separates it medially from the remainder of the endocavity. The root of the vagus $(\mathrm{CN} \mathrm{X})$ is small and rounded, and is directed posteriorly.

Elopoides (Figs. 4G,H and 5G,H). Although completely preserved, the specimen is slightly sheared, and the left horizontal and posterior semicircular canals are broken. The morphology of the labyrinth is posteriorly shifted and antero-posteriorly short when compared to the taxa described above. Most of the path of the anterior canal is uninvested in bone, and its small ampulla is very posteriorly placed underneath the crus commune. This latter feature projects above the endocranial roof. The external ampulla is poorly defined and widely separated from the anterior ampulla; the utriculus is barely discernible. The path of the posterior semicircular canal is almost straight, extending ventrally with very little curvature. Although the endocast as a whole is fairly narrow, the external canal is wide, and is isoclinally curved. The posterior ampulla is also small, and the horizontal canal enters the endocavity via this ampulla. Although posteriorly positional and inclined from the horizontal, the sacculus is large, with anterior and posterior notches. Although at first glance it appears absent, the vestige of a lateral 
cranial canal is indicated by a slight protrusion that begins ventral to the crus commune and continues anteriorly. There is no connection through the loop of the posterior canal. The root of the vagus $(\mathrm{CN} \mathrm{X})$ is small and rounded.

\section{DISCUSSION}

\section{Validation of previous models}

A portion of this study reinvestigated the labyrinth anatomy of 'Caturus' sp., one of the few fossil neopterygians for which a comprehensive description exists in the literature (Rayner, 1948). The results given in the previous section can be used to test the interpretations made on the basis of an endocranial plaster cast, produced as a result of serial grinding (Rayner, 1948: p.340-342). Rayner's depiction is broadly accurate, especially in the morphology of the lateral cranial canal, which almost exactly mirrors that seen in our reconstruction of the opposite side of the head, but many additional aspects of anatomy were not captured (e.g., the crus commune). The relative sizes of the canals is somewhat inexact in Rayner's illustrations (the horizontal canal is in fact somewhat shorter and the anterior rather longer than previously depicted), but this may be a constraint imposed by the lower resolution of her serial sectioning: Rayner achieved a slice thickness of $100 \mu \mathrm{m}$, whereas the slice thickness in our CT scan is 49 $\mu \mathrm{m}$. While the variation in the geometry of the canals between Rayner's interpretation and that given above may be a result of natural differences in opposing halves of the specimen, a similar asymmetry is not seen in any of the other taxa described above, and symmetry of the labyrinth is generally well documented in many groups (e.g., mammals: Welker et al., 2009). 
The labyrinth of Dorsetichthys bechei has also been previously reconstructed by Patterson (1975). Patterson did not section his specimen, and his account is based on an examination of the labyrinth cavities in sagittal view (1975: p. 336). While the general proportions of the canals are accurate and the ampullae are in the correct positions, the ampullae and utriculus are proportionally much smaller in Patterson's figure than in our model. The ventral extremity of the sacculus in his reconstruction seems greatly exaggerated. In other aspects, Patterson's description closely matches that given above, but his illustration (and text) fail to capture additional morphological features (e.g., the relationship between the labyrinth and cranial cavity).

The principal shortcoming with many past accounts is a failure--or inability-- to fully illustrate the labyrinth; although the descriptions are typically comprehensive, many features indicated in the current work have not been noted previously (e.g. the shape of the vagus root, the morphology of the sacculus, etc.). A lack of adequate illustration means that the presence or absence of these features cannot be corroborated without independent examination of the specimens, some of which have been destructively sectioned (e.g., half of 'Caturus': Rayner, 1948; many 'palaeoniscoid' endocasts: e.g., Nielsen, 1942). As hinted above, this may be due to the lower resolution offered by traditional techniques, combined with a possible loss of morphological characters in specimens that are fragmentary or incomplete. However written descriptions often capture features not shown in figures, for example Patterson's (1975) description of the narrow anterior connection of the lateral cranial canal in 'Caturus' sp., absent from Rayner's illustration (Rayner, 1948: fig. 9), suggests that many illustrations are stylized or simplified to some extent. Consequently existing accounts of labyrinth morphology 
in the literature should be treated with caution, particularly with respect to subtle or fine-scale morphological features.

\section{Can labyrinth characters inform neopterygian phylogeny?}

The new data presented in this study highlight a number of morphological features of the labyrinth and associated structures that are variable across our sample of taxa, such as the degree of enclosure of the semicircular canals by bone, dorsoventral elongation of the utriculus, and anteroposterior extension of the root of the vagus $(\mathrm{CN} \mathrm{X})$ nerve.. These features may well have some phylogenetic significance. In our discussion below, we have assessed character polarity based on conditions in Australosomus, the closest putative fossil relative of crown neopterygians for which structure of the endocavity and bony labyrinth is known in sufficient detail (Nielsen, 1949). However, given the discrepancies between our new models and past structural interpretations in neopterygians, character state assessments in Australosomus must of course be viewed tentatively.

Given the current state of uncertainty over how certain fossil taxa relate to living neopterygian clades, the taxa examined herein may follow one of four topologies, chiefly affected by the positions of Dapedium and parasemiontoids: Dapedium may be more closely related to holosteans (represented in this study only by halecomorphs) inclusive of parasemionotids (Patterson, 1975, 1977; Thies \& Waschkewitz, 2015; Fig. 6A); more closely related to holosteans exclusive of parasemionotids, with this group falling either on the neopterygian (Olsen, 1984, although this analysis considered Dapedium to be a stem teleost; Fig. 6B) or holostean stem (Wiley 1976; Grade \& 
Bemis, 1998; Fig. 6C); or more closely related to teleosts (Gardiner et al., 1996; Hurley et al., 2007; Xu \& Wu 2012; Fig. 6D). On the basis of morphological features of the labyrinth alone, we find no characters to support the first or last topologies (Figs 6A, D). When restricted to such characters, parsimony suggests that Dapedium is more closely related to holosteans (i.e., there are characters uniting it with holosteans, but not with teleosts; Fig. 7). As parasemionotids share no specialised inner characters with either holosteans or teleosts, there is insufficient evidence to select between a stem neopterygian, stem holostean or stem teleost placement on the basis of labyrinth morphology alone (Fig. 7). This ambiguity is perhaps unsurprising. Parasemionotids appear more primitive than crown holosteans in bearing well-developed clavicles and a plate-like preoperculum (Olsen, 1984), while some features classically cited as linking parasemionotids to halecomorphs appear to be broadly distributed among early neopterygians (e.g., a double jaw joint involving the sympletic, reported in both 'pholidophorids' and pycnodonts; Arratia, 2013; Poyato-Ariza, 2015).

\section{Bony labyrinth morphology in the earliest neopterygians}

Aside from the uncertainty surrounding the branching pattern of parasemionotids and Dapedium, this work finds a large number of characters in the bony labyrinth and associated structures supporting well-established clades (Fig. 7). The halecomorphs Heterolepidotus, 'Caturus' and 'Aspidorhynchus', as well as the incertae sedis genus Dapedium, all possess a dorsoventrally deep utriculus, an expanded, anteroposteriorly long root of the vagus $(\mathrm{CN} \mathrm{X})$ nerve, and show a wide separation between the lateral cranial canal and cranial cavity (Fig. 7, node 2). Exclusive of Dapedium, the long axis of the anterior ampulla of the former three taxa is oriented horizontally (Fig. 7, node 3). 
'Caturus' and 'Aspidorhynchus' are further united by the presence of a posterior notch in the saccular chamber and a lack of definition between the posterior ampulla and horizontal canal (Fig. 7, node 4). A relationship between the teleosts Dorsetichthys, Pholidophorus and Elopoides is supported by the lateral cranial canal and the cranial cavity being separated by only a very thin sheet of bone, and the posterior portion of the horizontal canal being entirely engulfed by the posterior ampulla (Fig. 7, node 5). 'Pholidophorus' and Elopoides are further united by an isoclinally curved horizontal canal and a partially uninvested anterior canal (Fig. 7, node 6).

It is difficult to assess whether the characters identified in Fig. 7 can be used to support placement of other early neopterygians for which the labyrinth has been described. So little is known about the morphology of the bony labyrinth in the parasemionotids Watsonulus, Devillersia and Ospia (Stensiö, 1932; Beltan, 1968) that identifying derived characters shared with the (also incomplete) parasemionotid described above is difficult. The accounts of labyrinth anatomy presented by Beltan (1968) do highlight a number of shared primitive features (as shown in Fig. 7), such as a small, subcircular root of the vagus $(\mathrm{CN} \mathrm{X})$ nerve, a rounded utriculus, and an anterior ampulla with a long axis oriented vertically. By contrast, it is more possible to discern potentially syanpomorphies in Caturus groenlandicus (Aldinger 1932), thanks partly to a more complete specimen (in which the endocast is preserved as a natural mould) accompanied by a more detailed illustration. This taxon possesses a wide separation between the lateral cranial canal and the cranial cavity, and the root of the vagus (CN X) nerve appears broad and anteroposteriorly long. These features are both shared with 'Caturus' and 'Aspidorhynchus', although other details concerning the condition of the 
utriculus, sacculus and ampullae cannot be discerned. The orientation at which the inner ear is reconstructed (i.e. medial) in the halecomorphs Ionoscopus and Calamopleurus (Maisey, 1999) makes it difficult to identify shared characters with the taxa described above.

Clearly this preliminary survey is not intended to be an exhaustive test of relationships, and it remains for these new characters to be incorporated into a more comprehensive anatomical analysis. We do not attempt this here given the small number of taxa in which labyrinth morphology is currently known in sufficient detail. Future work will seek to expand this dataset for both fossil and modern lineages. Obvious paleontological candidates include highly apomorphic fossil groups often interpreted as stem teleosts, such as pycnodonts, pachycormids, and aspidorynchids, as well as 'semionotids', an assemblage of stem-group gars. Three-dimensionally preserved neurocranial structures are known for each of these groups, although reduced ossification in some of them (e.g., 'semionotids') might make reconstruction and interpretation of endocasts difficult.

\section{Towards a more comprehensive understanding of labyrinth anatomy in early neopterygians}

The results presented in this work are necessarily preliminary, intended to show that the bony labyrinth and associated structures in neopterygians display a variety of morphological characters with the potential to inform phylogenetic hypotheses. Such information can now be easily unlocked by CT scanning of the abundant early neopterygian braincases known from the Triassic and Jurassic (e.g., Rayner, 1948; Gardiner, 1960; Patterson, 1975). Beyond this systematic application, new data on inner 
ears have potential to shed light on additional aspects of early neopterygian biology. Semicircular canal morphology has been shown to correlate with functional and ecological specialisation in a great variety of tetrapod groups (e.g. charadriiform birds: Smith \& Clarke, 2012; hominids: Spoor et al., 1994; mustelid nannaks: Grohé et al. 2015; rodents: Pfaff et al., 2015; snakes: Yi \& Norell, 2015). Few data exist to test this hypothesis in fishes, although Gauldie \& Radtke (1990) found evidence that the labyrinth morphology of the walking catfish Clarius fuscus, which is able to spend time on land, is more similar to those of terrestrial vertebrates than other fishes, suggesting that its inner ear shows adaptations towards a swaying (i.e. walking-like) rather than undulatory (i.e. swimming-like) gait. Using 3D data from CT scanning opens up the possibility of moving beyond simple linear measurements by applying threedimensional geometric morphometrics to compare shape data, which previous studies have established as a powerful technique for identifying phylogenetic and ecological correlates of labyrinth anatomy(e.g., Lebrun et al., 2010; Gunz et al., 2012; Benoit et al., 2015; Billet et al., 2015; Grohé et al., 2015).

\section{CONCLUSIONS}

The inner ears of early neopterygians exhibit morphological characters that may be of help in resolving phylogenetic relationships amongst problematic clades. The characters highlighted in this work suggest that Dapedium may be allied more closely to holosteans than teleosts, and find no additional evidence for parasemionotids being halecomorphs or even holosteans. A wider understanding of inner ear and bony labyrinth morphology in extinct and extant neopterygians is hampered by a dearth of published accounts. Additional data will test whether morphological innovation in the 
labyrinths of neopterygian fishes (both living and extinct) accompanies diversification into new habitats and ecological niches, as has been inferred for other groups across the Tree of Life (Ekdale et al., 2016; Ni et al., 2010; Spoor et al., 1994, 2002; Yi \& Norell, 2015).

\section{Acknowledgements}

The authors thank Cathrin Pfaff, Julia Schultz and Rico Schellhorn for the invitation to contribute to this issue. Roger Close, Zerina Johanson, Dan Sykes, Rebecca Summerfield and Miguel Garcia Sanz assisted with CT scanning. Donald Davense helped coordinate specimen access at MNHN. Stig Walsh and an anonymous reviewer provided useful comments on improving the manuscript. Support for tomographic analyses and computational infrastructure for processing resulting data was provided by the Leverhulme Trust (Research Project Grant RPG-2012-658, Philip Leverhulme Prize PLP-2012-130; both to MF). Funding for SG was provided by a Junior Research Fellowship from Christ Church, Oxford.

\section{REFERENCES}

Aldinger H. 1932. Über einen Eugnathiden aus der unteren Wolgastufe von Ostgrönland. Meddr Grønland 86:1-51.

Arratia G. 2013. Morphology, taxonomy, and phylogeny of Triassic pholidophorid fishes (Actinopterygii, Teleostei). J Vertebr Paleontol (suppl.) 33:1-138. 
Beltan L. 1968. La faune ichthyologique de l'Eotrias du N.W. de Madagascar: le neurocrâne. Paris: Éditions du C.N.R.S. 135p.

Benoit J, Lehmann T, Vatter M, Lebrun R, Merigeaud S, Costeur L, Tabuce R. 2015. Comparative anatomy and three-dimensional geometric-morphometric study of the bony labyrinth of Bibymalagasia (Mammalia, Afrotheria). J Vertebr Paleontol 35:e930043.

Bernacsek GM, Carroll RL. 1981. Semicircular canal size in fossil fishes and amphibians. Can J Earth Sci 18:150-156.

Billet G, Hautier L, Lebrun R. 2015. Morphological diversity of the bony labyrinth (inner ear) in extant xenarthrans and its relation to phylogeny. J Mammal :gyv074.

de Burlet HM. 1934. Vergleichende Anatomie des stato-akustischen Organs. Handbuch der vergleichenden Anatomie der Wirbeltiere 1293-1380.

Cope ED. 1871. Observations on the systematic relations of the fishes. Am Nat 5:57993.

Dunkle DH. 1940. The cranial osteology of Notelops brama (Agassiz), an elopid fish from the Cretaceous of Brazil. Lloydia 3:157-190.

Ekdale EG. 2016. Form and function of the mammalian inner ear. J Anat 228:324-337. 
Friedman M. 2012. Ray-finned fishes (Osteichthyes, Actinopterygii) from the type Maastrichtian, the Netherlands and Belgium. Scripta GeolSpecial Issue 8:113-42.

Frost GA. 1913. The internal cranial elements and foramina of Dapedius granulatus, from a specimen recently found in the Lias at Charmouth. Q J Geol 69:219-22.

Gauldie RW, Radtke RL. 1990. Using the physical dimensions of the semicircular canal as a probe to evaluate inner ear function in fishes. Comparative Biochemistry and Physiology Part A: Physiology 96:199-203.

Gardiner BG. 1960. A revision of certain actinopterygian and coelacanth fishes, chiefly from the Lower Lias. Bull Br Mus Nat Hist Geol 4:239-384.

Gardiner BG, Maisey JG, Littlewood DT. 1996. Interrelationships of basal neopterygians. In: Stiassny MLJ, Paenti LR, Johnson GD. Interrelationships of fishes. London: Academic Press. p 117-146.

Giles S, Friedman M. 2014. Virtual reconstruction of endocast anatomy in early rayfinned fishes (Osteichthyes, Actinopterygii). J Paleontol 88:636-651.

Giles S, Darras L, Clément G, Blieck A, Friedman M. (2015a). An exceptionally preserved Late Devonian actinopterygian provides a new model for primitive cranial anatomy in ray-finned fishes. Proc R Soc London, Ser B 282:20151485. 
Giles S, Friedman M, Brazeau MD. 2015b. Osteichthyan-like cranial conditions in an Early Devonian stem gnathostome. Nature 520:82-85.

Grande L. 2010. An empirical synthetic pattern study of gars (Lepisosteiformes) and closely related species, based mostly on skeletal anatomy. The resurrection of Holostei. American Society of Ichthyologists and Herpetologists Special Publication 6:1-871.

Grande L, Bemis. WE. 1998. A comprehensive phylogenetic study of amiid fishes (Amiidae) based on comparative skeletal anatomy. An empirical search for interconnected patterns of natural history. Society of Vertebrate Paleontology Memoir 4:1-690.

Grohé C, Tseng ZJ, Lebrun R, Boistel R, Flynn JJ. 2015. Bony labyrinth shape variation in extant Carnivora: a case study of Musteloidea. J Anat

Gunz P, Ramsier M, Kuhrig M, Hublin JJ, Spoor F. 2012 The mammalian bony labyrinth reconsidered, introducing a comprehensive geometric morphometric approach. J Anat 6:529-43.

Hamel M-H, Poplin C. 2008. The braincase anatomy of Lawrenciella schaefferi, actinopterygian from the Upper Carboniferous of Kansas (USA). J Vertebr Paleontol 28:989-1006. 
Howland HC, Masci J. 1973a. The phylogenetic allometry of the semicircular canals of small fishes. Z Morphol Tiere 75:283-96.

Howland HC, Masci J. 1973b. The functional allometry of semicircular canals, fins, and body dimensions in the juvenile centrarchid fish, Lepomis gibbosus (L.). Development 29:721-43.

Hurley IA, Mueller RL, Dunn KA, Schmidt EJ, Friedman M, Ho RK, Prince VE, Yang Z, Thomas MG, Coates MI. 2007. A new time-scale for ray-finned fish evolution. Proc R Soc London, Ser B 274:489-98.

Hullar TE. 2006. Semicircular canal geometry, afferent sensitivity, and animal behavior. Anat Rec Part A 288:466-72.

Jenkins DB. 1977. A light microscopic study of the saccule and lagena in certain catfishes. Am J Anat 150:605-29.

Jones GM, Spells KE. 1963. A theoretical and comparative study of the functional dependence of the semicircular canal upon its physical dimensions. Proc R Soc London, Ser B 157:403-19.

Ladich F, Popper AN. 2004. Parallel evolution in fish hearing organs. In: Manley GA, Fay RR, Popper AN, editors. Evolution of the vertebrate auditory system 2004 (pp. 95 127). Springer: New York. p 95-127. 
Giles 28

Lebrun R, De León MP, Tafforeau P, Zollikofer C. 2010. Deep evolutionary roots of strepsirrhine primate labyrinthine morphology. J Anat 216:368-80.

Maisey JG. 1999. The supraotic bone in neopterygian fishes (Osteichthyes, Actinopterygii). Am Mus Novit 3267:1-52.

Maisey JG. 2001. Remarks on the inner ear of elasmobranchs and its interpretation from skeletal labyrinth morphology. J Morphol 250:236-64.

Moodie RL. 1929. On a New Specimen of a Paleoniscid Brain from Iowa. Iowa Geological Survey Annual Report 35:489-98.

Müller J. 1844. Über den Bau und die Grenzen der Ganoiden und über das natürliche System der Fische. Behricht Akademie der Wissenschaften Berlin 1844:416-422.

Near TJ, Eytan RI, Dornburg A, Kuhn KL, Moore JA, Davis MP, Wainwright PC, Friedman M, Smith WL. 2012. Resolution of ray-finned fish phylogeny and timing of diversification. Proc Natl Acad Sci USA 109: 13698-13703.

Ni X, Flynn JJ, Wyss AR. 2010. The bony labyrinth of the early platyrrhine primate Chilecebus. J Hum Evol 59:595-607. 
Nielsen E. 1942.Studies on Triassic fishes from East Greenland. I. Glaucolepis and Boreosomus. Meddr Grønland 138:1-403.

Nielsen E. 1949. Studies on Triassic fishes from East Greenland. II. Australosomus and Birgeria. Meddr Grønland 146:1-309.

Nursall JR. The case for pycnodont fishes as the fossil sister-group of teleosts. In:

Nelson JS, Schultze, H-P, Wilson, MVH. Origin and phylogenetic interrelationships of teleosts. Munich: Verlag Dr. Friedrich Pfeil. 37-60.

Olsen PE. 1984. The skull and pectoral girdle of the parasemionotid fish Watsonulus eugnathoides from the Early Triassic Sakamena Group of Madagascar, with comments on the relationships of the holostean fishes. J Vertebr Paleontol 4:481-499.

Patterson C. 1973. Interrelationships of holosteans. In: Greenwood PH, Miles, RS, Patterson, C, editors. Interrelationships of fishes. London: Academic Press. p 233-305.

Patterson, C. 1975. The braincase of pholidophorid and leptolepid fishes, with a review of the actinopterygian braincase. Philos T R Soc B 269:275-579.

Patterson, C. 1977. The contribution of paleontology to teleostean phylogeny. In: Hecht MK, Goody PC, Hecht BM, editors. Major patterns in vertebrate evolution. New York: Plenum Press p 579-643. 
Pfaff C, Martin T, Ruf I. 2015. Bony labyrinth morphometry indicates locomotor adaptations in the squirrel-related clade (Rodentia, Mammalia). Proc R Soc B 282:20150744.

Poyato-Ariza FJ. 2015. Studies on pycnodont fishes (I): evaluation of their phylogenetic position among actinopterygians. Riv Ital Paleontol

$121: 329-343$.

Poplin C. 1974. Étude de quelques paléoniscidés pennsylvaniens du Kansas. Paris: Éditions du C.N.R.S. 151 p.

Popper AN, Tavolga WN. 1981. Structure and function of the ear in the marine catfish, Arius felis. J Comp Physiol A: Neuroethology, Sensory, Neural, and Behavioral Physiology 144:27-34.

Popper AN, Fay RR, Platt C, Sand O. 2003. Sound detection mechanisms and capabilities of teleost fishes. In: Collin SP, Marchall NJ, editors. Sensory processing in aquatic environments. New York: Springer. p 3-38.

Rayner DM. 1948. The structure of certain Jurassic holostean fishes, with special reference to their neurocrania. Philos T R Soc B 233:287-345.

Regan CT. 1923. The skeleton of Lepidosteus, with remarks on the origin and evolution of the lower neopterygian fishes. P Zool Soc Lond 93:445-461. 
Retzius G. 1881. Das Gehörorgan der Fische und Amphibien. Stockholm: Samson and Wallin. $222 \mathrm{p}$.

Rogers SW. 1999. Allosaurus, crocodiles, and birds: evolutionary clues from spiral computed tomography of an endocast. Anat Rec 257:162-73.

Rogers BD. 2008. Morphology of the inner and peripheral ear of the loricariid catfish Pterygoplochthtys gibbiceps K. [dissertation]. Kentucky: Western Kentucky University. $35 \mathrm{p}$.

Schaeffer B. 1968. The origin and basal radiation of the Osteichthyes. In Ørvig T, editor. Current problems in lower vertebrate phylogeny. Nobel Symposium, Stockholm, $4207-222$.

Thies D, Waschkewitz J. In press. Redescription of Dapedium pholidotum (Agassiz, 1832) (Actinopterygii, Neopterygii) from the Lower Jurassic Posidonia Shale, with comments on the phylogenetic position of Dapedium Leach, 1822. J Syst Palaeontol

Woodward AS. 1893. On the cranial osteology of the Mesozoic ganoid fishes, Lepidotus and Dapedius. P Zool Soc Lond 38:559-565.

Wenz S. 1965. Les poisssons albiens de Vallentigny (Aube). Annal Paléontol Vertébr 51: $1-23$ 
Wenz S. 1968. Compléments a l'étude des poisons actinopterygians du Jurassique fraçaise. Paris: Centre national de le recherché scientifique. 276 p.

Woodward AS. 1895. Catalogue of the Fossil Fishes in the British Museum:(Natural History.) London: British Museum (Natural History). 544 p.

Woodward AS. 1918. The fossil fishes of the English Wealden and Purbeck formations. Cambridge University Press.

Smith NA, Clarke JA. 2012. Endocranial anatomy of the Charadriiformes: sensory system variation and the evolution of wing-propelled diving. PloS one 7:e49584.

Spoor F, Bajpai S, Hussain ST, Kumar K, Thewissen JG. 2002. Vestibular evidence for the evolution of aquatic behaviour in early cetaceans. Nature 417:163-6.

Spoor F, Wood B, Zonneveld F. 1994. Implications of early hominid labyrinthine morphology for evolution of human bipedal locomotion. Nature 369:645-8.

Stensiö EA. 1924. Triassic fishes from Spitzbergen. K svenska VetenskAkad Handl $2: 1-261$

Stensiö EA 1932. Triassic fishes from East Greenland collected by the Danish expeditions in 1929-1931. Meddr Grønland 83:1-305. 
Giles 33

ten Kate JH. 1969. The oculo-vestibulo reflex of the growing pike [dissertation]. The Netherlands: University of Groningen.

Ten Kate JH, Van Barneveld HH, Kuiper JW. 1970. The dimensions and sensitivities of semicircular canals. J Exp Biol. 53:501-14.

Thies D, Herzog A. 1999. New information on †Dapedium LEACH 1822 (Actinopterygii, †Semionotiformes). In: Arratia, G, Schultze, H-P, editors. Munich: Verlag Dr. Friedrich Pfeil. p 143-52.

Tintori TAH. 1983. Hypsisomatic Semionotidae (Pisces, Actinopterygii) from the Upper Triassic of Lombardy (N. Italy). Riv Ital Paleontol, 88, 417-442.

Welker KL, Orkin JD, Ryan TM. 2009. Analysis of intraindividual and intraspecific variation in semicircular canal dimensions using high $\square$ resolution $\mathrm{x} \square$ ray computed tomography. J Anat 215:444-51.

Wenz S. 1968. 1968. Compléments à l'étude des poisons Actinopterigiens du Jurassique français. Paris: Éditions du C.N.R.S. 276p.

Wiley EO. 1976. The phylogeny and biogeography of fossil and recent gars (Actinopterygii: Lepisosteidae). Miscellaneous Publications, museum of Natural History, University of Kansas 64:1-11. 
Giles 34

Xu G, Wu F. 2012. A deep-bodied ginglymodian fish from the Middle Triassic of eastern Yunnan Province, China, and the phylogeny of lower neopterygians. Chinese Sci Bull 57:111-8.

Yi H, Norell MA. 2015. The burrowing origin of modern snakes. Science Advances e1500743.

Fig. 1. Pre-existing accounts of fossil neopterygian bony labyrinth structure. A: Caturus groendlandicus in dorsal view (modified from Aldinger, 1937). B: 'Caturus' sp. in dorsal view (modified from Rayner, 1948). C: Watsonulus sp. (modified from Beltan, 1968). D: Devillersia madagascariensis in dorsal view (modified from Beltan, 1968). E: Devillersia madagascariensis in lateral view (modified from Beltan, 1968). F: Ospia sp. in lateral view (modified from Stensiö, 1932). G: Dorsetichthys bechei in lateral and medial view (modified from Patterson, 1975). H: Calamopleurus cylindricus in sagittal view (modified from Maisey, 1999). I: Ionoscopus cyprinoides in sagittal view (modified from Maisey, 1999).

Fig. 2. Three dimensional renderings of endocast and bony labyrinth structure. Undertermined parasemionotid (MGUH 492) in A: right lateral (image flipped to 
resemble left lateral) and B: dorsal view. Heterolepidotus sp. (NHMUK PV P.13260) in C: left and D: dorsal view. 'Caturus' sp. (BRSLI M.1288A) in E: left and F: dorsal view (right half of specimen lost, so left half is mirrored and faded). 'Aspidorhynchus' (NHMUK PV P.9844) in G: left and H: dorsal view. Scale bar in all is $10 \mathrm{~mm}$.

Fig. 3. Interpretive drawings of endocast and bony labyrinth structure. Oblique lines indicate broken surfaces. Undertermined parasemionotid (MGUH 492) in A: right lateral (image flipped to resemble left lateral) and B: dorsal view. Heterolepidotus sp. (NHMUK PV P.13260) in C: left and D: dorsal view. 'Caturus' sp. (BRSLI M.1288A) in $\mathbf{E}$ : left and F: dorsal view (right half of specimen lost, so left half is mirrored and faded). 'Aspidorhynchus' sp. (NHMUK PV P.9844) in G: left and H: dorsal view. Scale bar in all is $10 \mathrm{~mm}$. aa, anterior ampulla; asc, anterior semicircular canal; end, endolymphatic duct; ha, horizontal ampulla; hsc, horizontal semicircular canal; lcc, lateral cranial canal; olf, olfactory tract; optl, optic lobe; psc, posterior semicircular canal; sac, sacculus; utr, utriculus; vag, vagus nerve.

Fig. 4. Three dimensional renderings of endocast and bony labyrinth structure. Dapedium sp. (NHMUK PV P.11177) in A: left lateral and B: dorsal view. Dorsetichthys bechei (NHMUK PV P.1052) in C: right lateral (image flipped to resemble left lateral) and D: dorsal view. 'Pholidophorus' sp. (NHMUK PV P.32579) in E: left and F: dorsal view. Elopoides tomassoni (MNHN CTE 14 in G: left and H: dorsal view. Scale bar in all is $5 \mathrm{~mm}$. 
Fig. 5. Interpretive drawings of endocast and bony labyrinth structure. Oblique lines indicate broken surfaces; stippling indicates regions of inner ear uninvested in bone. Dapedium sp. (NHMUK PV P.11177) in A: left lateral and B: dorsal view. Dorsetichthys bechei (NHMUK PV P.1052) in C: right lateral (image flipped to resemble left lateral) and D: dorsal view. 'Pholidophorus' sp. (NHMUK PV P.32579) in E: left and F: dorsal view. Elopoides tomassoni (MNHN CTE 14 in G: left and H: dorsal view. Scale bar in all is $5 \mathrm{~mm}$. aa, anterior ampulla; asc, anterior semicircular canal; end, endolymphatic duct; ha, horizontal ampulla; hsc, horizontal semicircular canal; lcc, lateral cranial canal; olf, olfactory tract; optl, optic lobe; psc, posterior semicircular canal; sac, sacculus; trfa, trigeminofacialis chamber; utr, utriculus; vag, vagus nerve.

Fig. 6. Alternative tree topolgies amongst early neopterygians. A: based on Patterson, 1975, 1977; B: based on Olsen, 1984; C: based on Wiley 1976; Grade \& Bemis, 1998; D: based on Gardiner et al., 1996; Hurley et al.,. 2007; Xu \& Wu 2012.

Fig. 7. Character evolution in the bony labyrinth of early neopterygians. Potential synapomorphies are given at successive nodes. A: Dapedium sp. B: Heterolepidotus sp. C: 'Caturus' sp. D: 'Aspidorhynchus' sp. E: Undetermined parasemionotid. F: Dorsetichthys bechei. G: 'Pholidophorus' sp. H: Elopoides tomassoni. 1: semicircular canals fully invested in bone; long axis of anterior ampulla oriented vertically; posterior portion of horizontal canal disctinct within posterior ampulla; lateral cranial canal has anterior and posterior connection to cranial cavity; root of vagus ( $\mathrm{CN} \mathrm{X})$ nerve rounded. 2: wide separation between lateral cranial canal and cranial cavity; utriculus deep; root 
of vagus $(\mathrm{CN} \mathrm{X})$ nerve large and anteroposteriorly long. 3: long axis of anterior ampulla oriented horizontally. 4: posterior portion of horizontal canal completely engulfed by posterior ampulla; narrow separation between lateral cranial canal and cranial cavity; sacculus has posterior notch. 5: posterior portion of horizontal canal completely engulfed by posterior ampulla; lateral cranial canal and cranial cavity separated by only a thin sheet of bone. 6: anterior canals partially uninvested in bone; horizontal canal curved isoclinally. 
A
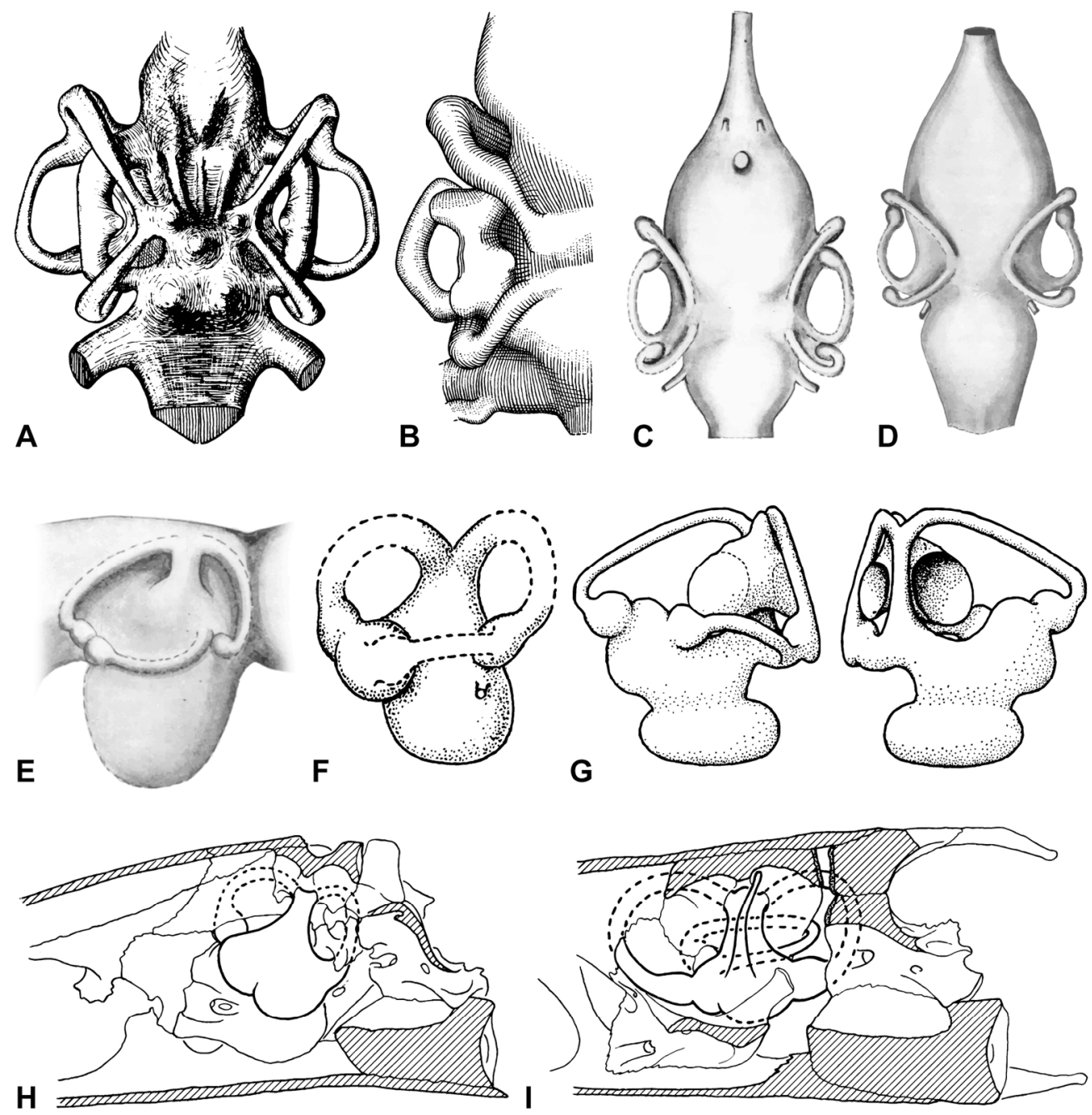

Pre-existing accounts of neopterygian and inner ear structure. A: Caturus groendlandicus in dorsal view (modified from Aldinger, 1937). B: 'Caturus' sp. in dorsal view (modified from Rayner, 1948). C: Watsonulus sp. (modified from Beltan, 1968). D: Devillersia madagascariensis in dorsal view (modified from Beltan, 1968). E: Devillersia madagascariensis in lateral view (modified from Beltan, 1968). F: Ospia sp. in lateral view (modified from Stensiö, 1932). G: Dorsetichthys bechei in lateral and medial view (modified from Patterson, 1975). H: Calamopleurus cylindricus in sagittal view (modified from Maisey, 1999). I: Ionoscopus cyprinoides in sagittal view (modified from Maisey, 1999). $155 \times 160 \mathrm{~mm}(300 \times 300 \mathrm{DPI})$ 
A
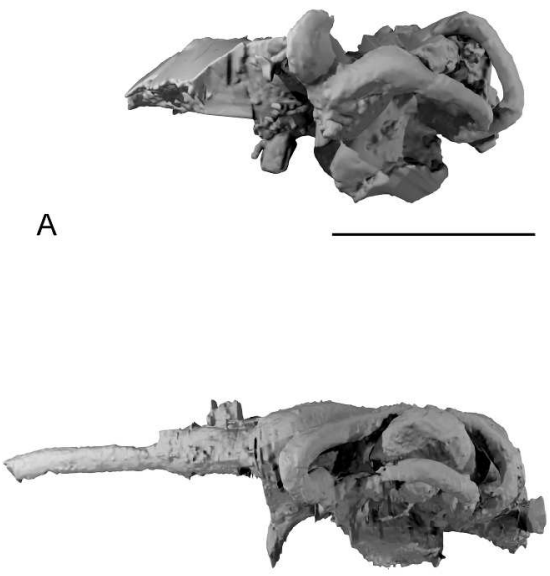

C

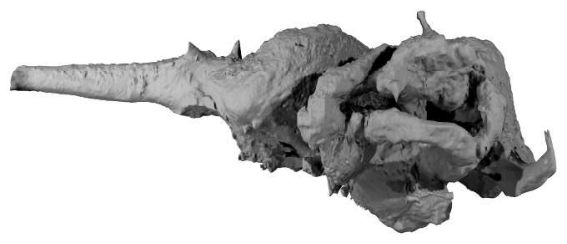

E

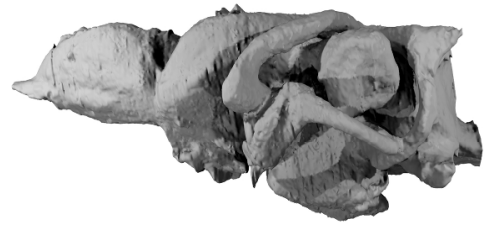

B
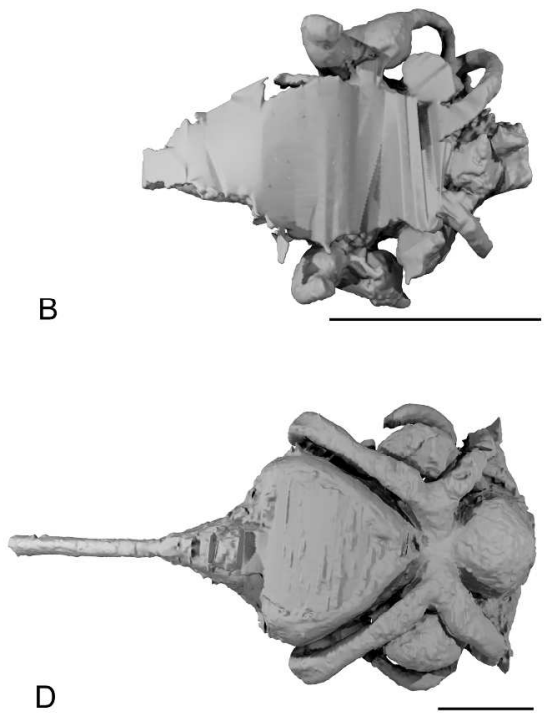

F

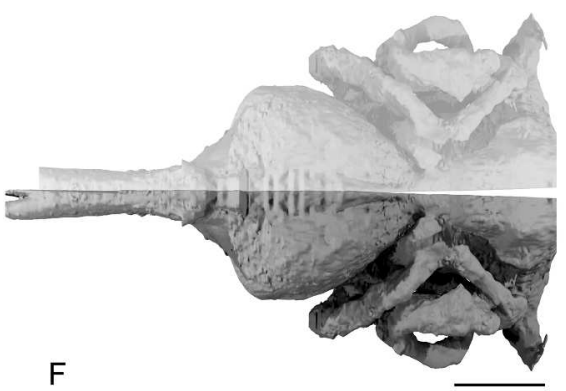

$\mathrm{H}$

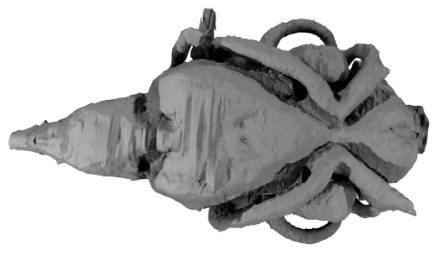

Three dimensional renderings of endocast and inner ear structure. Undertermined parasemionotid (MGUH 492) in A: right lateral (image flipped to resemble left lateral) and B: dorsal view. Heterolepidotus sp. (NHMUK PV P.13260) in C: left and D: dorsal view. 'Caturus' sp. (BRSLI M.1288A) in E: left and F: dorsal view (right half of specimen lost, so left half is mirrored and faded). 'Aspidorhynchus' (NHMUK PV P.9844) in $\mathrm{G}$ : left and $\mathrm{H}$ : dorsal view. Scale bar in all is $10 \mathrm{~mm}$. $214 \times 296 \mathrm{~mm}(300 \times 300$ DPI $)$ 
A

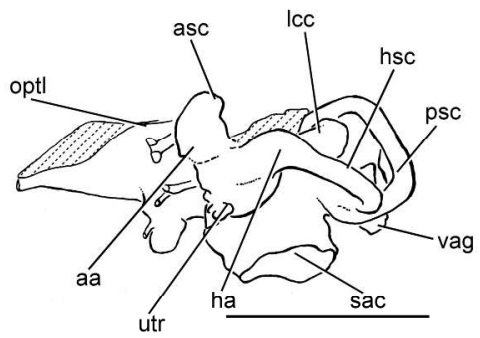

B

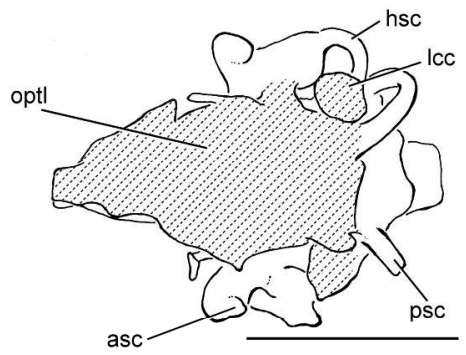

Interpretive drawings of endocast and inner ear structure. Oblique lines indicate broken surfaces. Undertermined parasemionotid (MGUH 492) in A: right lateral (image flipped to resemble left lateral) and B: dorsal view. Heterolepidotus sp. (NHMUK PV P.13260) in C: left and D: dorsal view. 'Caturus' sp. (BRSLI $\mathrm{M} .1288 \mathrm{~A}$ ) in $\mathrm{E}$ : left and $\mathrm{F}$ : dorsal view (right half of specimen lost, so left half is mirrored and faded).

'Aspidorhynchus' sp. (NHMUK PV P.9844) in G: left and H: dorsal view. Scale bar in all is $10 \mathrm{~mm}$. aa, anterior ampulla; asc, anterior semicircular canal; end, endolymphatic duct; ha, horizontal ampulla; hsc, horizontal semicircular canal; Icc, lateral cranial canal; olf, olfactory tract; optl, optic lobe; psc, posterior semicircular canal; sac, sacculus; utr, utriculus; vag, vagus nerve. $214 \times 296 \mathrm{~mm}$ (300 × 300 DPI) 


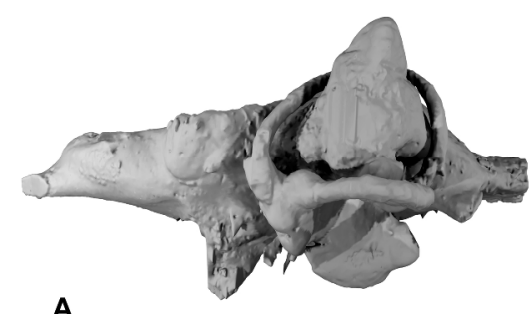

A

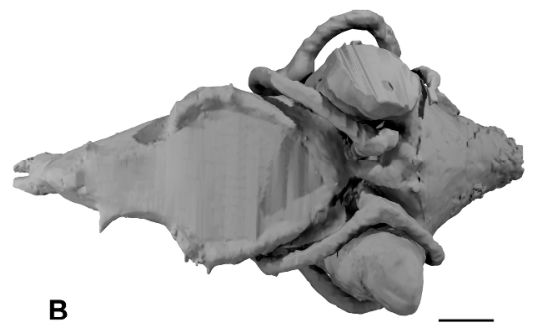

C
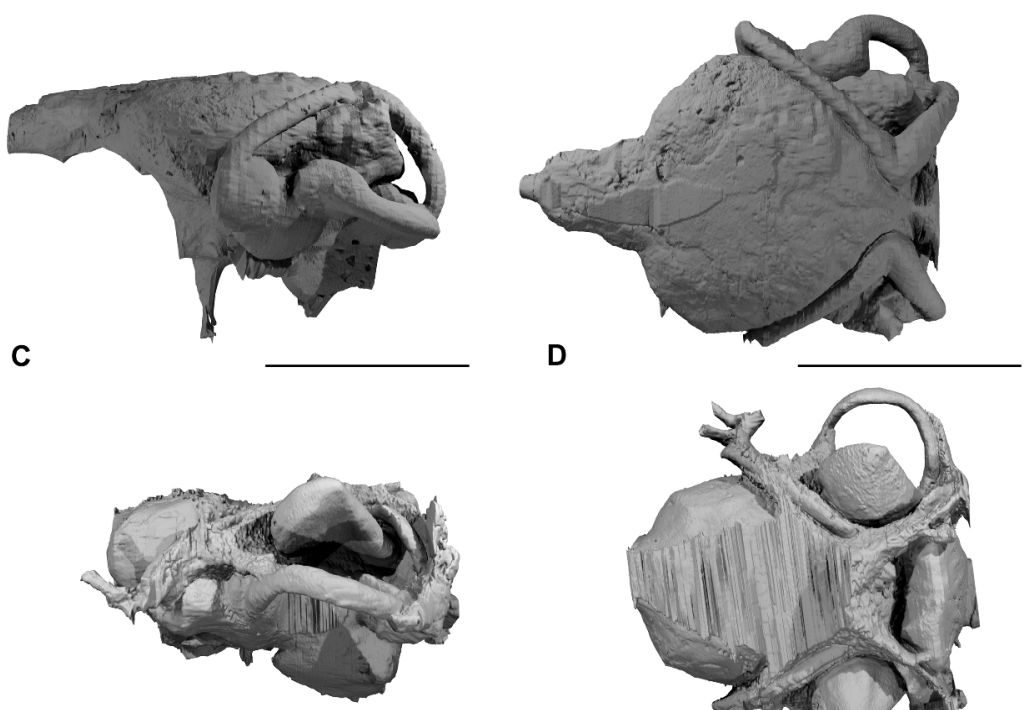

E

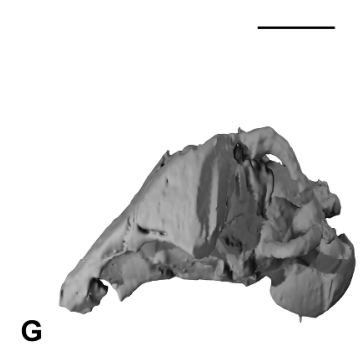

G

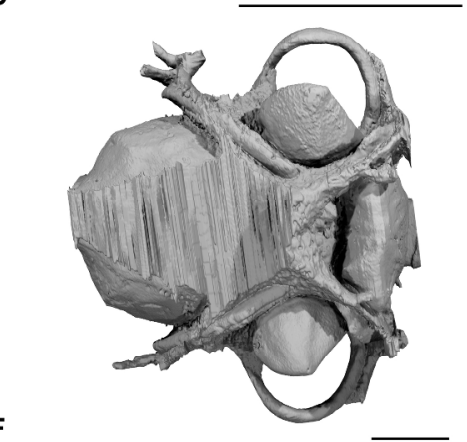

F

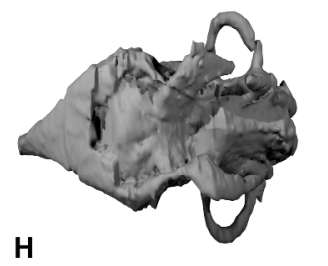

Three dimensional renderings of endocast and inner ear structure. Dapedium sp. (NHMUK PV P.11177) in A: left lateral and B: dorsal view. Dorsetichthys bechei (NHMUK PV P.1052) in C: right lateral (image flipped to resemble left lateral) and D: dorsal view. 'Pholidophorus' sp. (NHMUK PV P.32579) in E: left and F: dorsal view. Elopoides tomassoni (MNHN CTE 14 in G: left and H: dorsal view. Scale bar in all is $5 \mathrm{~mm}$. $230 \times 341 \mathrm{~mm}(300 \times 300 \mathrm{DPI})$ 

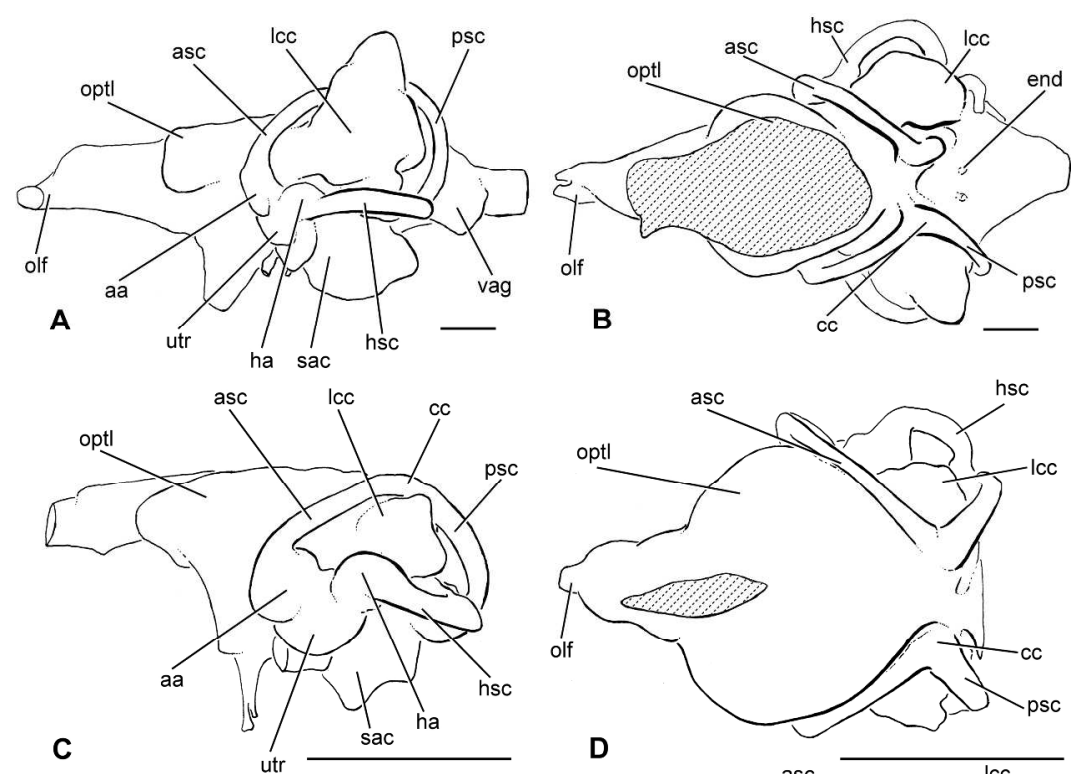

c
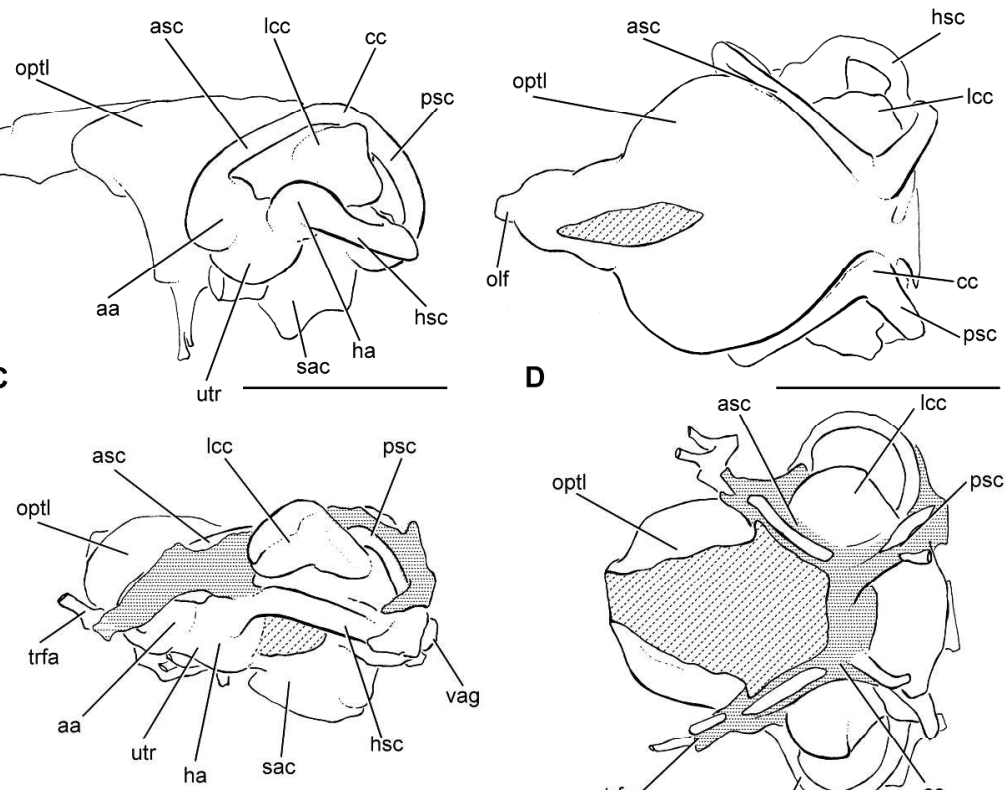

E
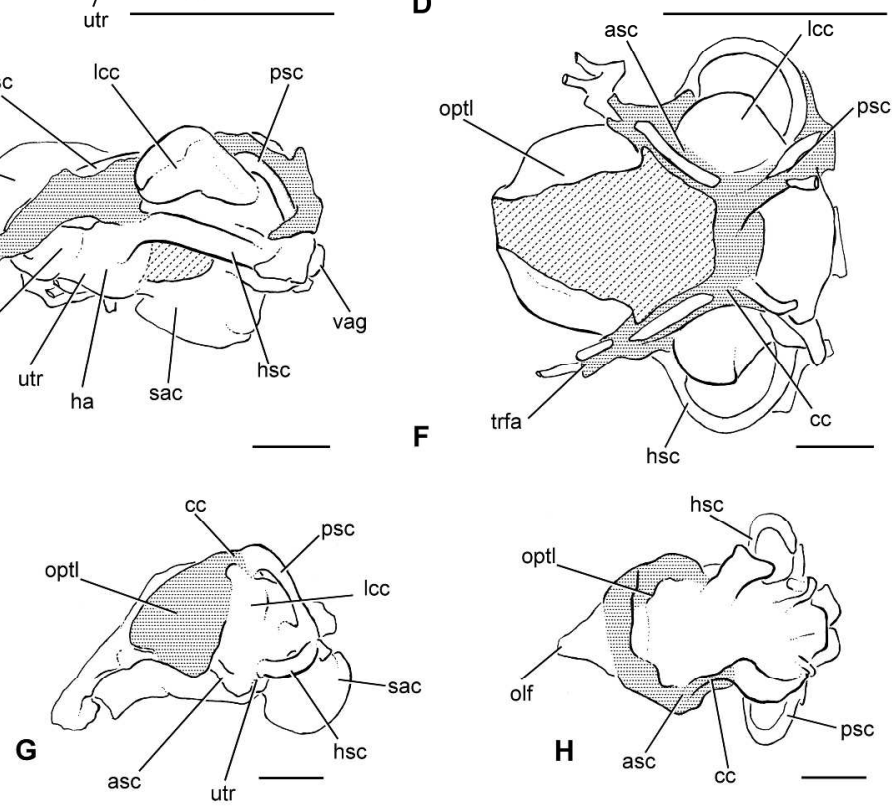

Interpretive drawings of endocast and inner ear structure. Oblique lines indicate broken surfaces; stippling indicates regions of inner ear uninvested in bone. Dapedium sp. (NHMUK PV P.11177) in A: left lateral and B: dorsal view. Dorsetichthys bechei (NHMUK PV P.1052) in C: right lateral (image flipped to resemble left lateral) and D: dorsal view. 'Pholidophorus' sp. (NHMUK PV P.32579) in E: left and F: dorsal view. Elopoides tomassoni (MNHN CTE 14 in G: left and H: dorsal view. Scale bar in all is $5 \mathrm{~mm}$. aa, anterior ampulla; asc, anterior semicircular canal; end, endolymphatic duct; ha, horizontal ampulla; hsc, horizontal semicircular canal; Icc, lateral cranial canal; olf, olfactory tract; optl, optic lobe; psc, posterior semicircular canal; sac, sacculus; trfa, trigeminofacialis chamber; utr, utriculus; vag, vagus nerve. $230 \times 340 \mathrm{~mm}(300 \times 300 \mathrm{DPI})$ 

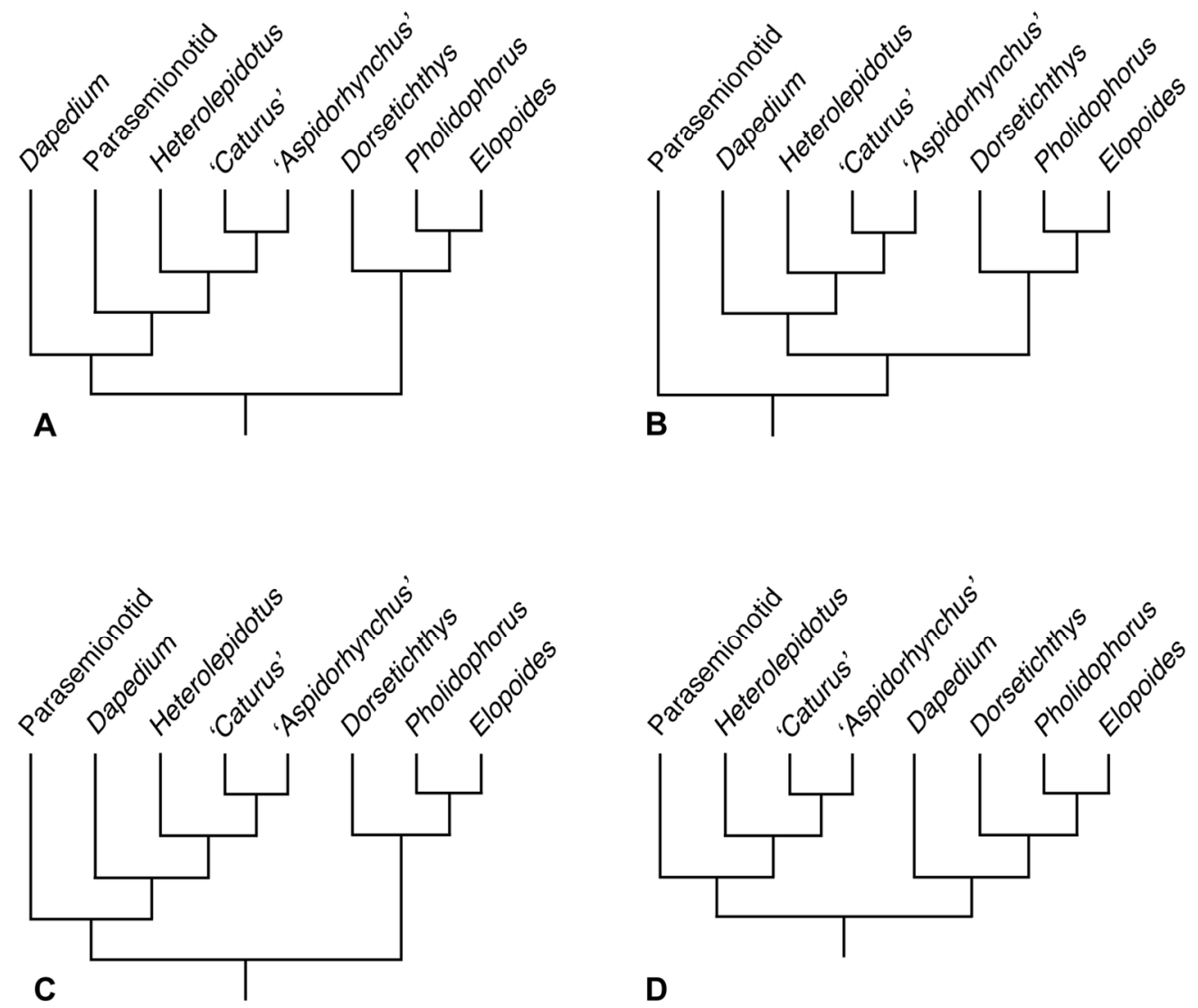

D

Fig. 6. Alternative tree topologies amongst early neopterygians. A: based on Patterson, 1975, 1977; B: based on Olsen, 1984; C: based on Wiley 1976; Grade \& Bemis, 1998; D: based on Gardiner et al., 1996; Hurley et al., 2007; Xu \& Wu 2012. $132 \times 113 \mathrm{~mm}(300 \times 300 \mathrm{DPI})$ 
Character evolution in the bony labyrinth of early neopterygians. Potential synapomorphies are given at successive nodes. A: Dapedium sp. B: Heterolepidotus sp. C: 'Caturus' sp. D: 'Aspidorhynchus' sp. E: Undetermined parasemionotid. F: Dorsetichthys bechei. G: 'Pholidophorus' sp. H: Elopoides tomassoni. 1: semicircular canals fully invested in bone; long axis of anterior ampulla oriented vertically; posterior portion of horizontal canal disctinct within posterior ampulla; lateral cranial canal has anterior and posterior connection to cranial cavity; root of vagus $(\mathrm{CN} \mathrm{X)}$ nerve rounded. 2: wide separation between lateral cranial canal and cranial cavity; utriculus deep; root of vagus (CN X) nerve large and anteroposteriorly long. 3: long axis of anterior ampulla oriented horizontally. 4: posterior portion of horizontal canal completely engulfed by posterior ampulla; narrow separation between lateral cranial canal and cranial cavity; sacculus has posterior notch. 5: posterior portion of horizontal canal completely engulfed by posterior ampulla; lateral cranial canal and cranial cavity separated by only a thin sheet of bone. 6: anterior canals partially uninvested in bone; horizontal canal curved isoclinally.

$61 \times 24 \mathrm{~mm}(300 \times 300$ DPI $)$ 